\title{
Aquarius Radiometer Status
}

\author{
D. M. Le Vine and J.R. Piepmeier \\ Goddard Space Flight Center, \\ Greenbelt, MD 20771
}

\section{E.P. Dinnat}

Chapman University, Goddard Space Flight Center

Greenbelt, MD 20771

\author{
P. de Matthaeis and C. Utku \\ USRA/GESTAR, Goddard Space Flight Center \\ Greenbelt, MD 20771
}

\author{
S. Abraham \\ Greenbelt, MD 20771 \\ G.S.E Lagerloef \\ Earth and Space Research \\ Seattle, WA 98121 \\ T. Meissner and F. Wentz \\ Remote Sensing Systems \\ Santa Rosa, CA 95401
}

Wyle Information Systems, Goddard Space Flight Center

\begin{abstract}
Aquarius was launched on June 10, 2011 as part of the Aquarius/SAC-D observatory and the instrument has been operating continuously since being turned on in August of the same year. The initial map of sea surface salinity was released one month later (September) and the quality of the retrieval has continuously improved since then. The Aquarius radiometers include several special features such as measurement of the third Stokes parameter, fast sampling, and careful thermal control, and a combined passive/active instrument. Aquarius is working well and in addition to helping measure salinity, the radiometer special features are generating new results.
\end{abstract}

Keywords-Microwave Remote Sensing; L-band; Radiometry

\section{INTRODUCTION}

Aquarius is an instrument on the Aquarius/SAC-D observatory, a partnership between NASA which developed Aquarius and the Argentine space agency, CONAE, which developed the observatory bus, called SAC-D, and several instruments [1]. Figure 1 is a drawing showing the observatory in its deployed configuration. Aquarius is the structure on the left. It consists of three radiometers (three feeds and a $2.5 \mathrm{~m}$ reflector). The radiometer beams image in pushbroom fashion with the beams looking to the left, approximately in the plane of the figure, and covering a swath of $390 \mathrm{~km}$ [1]. The feeds are shared by the radiometer and scatterometer which are designed to look at the same spot on the surface at approximately the same time. The radiometer is the primary instrument for the measurement of salinity and the scatterometer provides a measurement to help correct for surface roughness which is a major potential source of error [2, 3]. The radiometers measure horizontal and vertical polarization and the third Stokes parameter (real part of the correlation of the two polarizations). This is to provide a realtime correction for Faraday rotation [4] which is important at L-band [5]. Both the radiometer and the scatterometer sample rapidly (one measurement each $10 \mathrm{~ms}$ ) to help mitigate effects of RFI. The principle being that by sampling rapidly, those samples corrupted by RFI can be removed and still leave sufficient samples to make a reasonable measurement in each approximately $100 \mathrm{~km}$ x $100 \mathrm{~km}$ pixel. Finally, the spacecraft is oriented to fly on the day-night terminator $(6 \mathrm{pm}$ ascending orbit) with the beams looking toward the night-time side of the Earth to avoid sun-glint as much as possible [6]. In addition, attention was paid in the design of the reflector to minimize sidelobes in the direction of the direct and reflected rays from the Sun (to the right of the observatory in Figure 1) which can be an important and variable source of unwanted signal at Lband. These special features plus an internal calibration and careful attention to thermal control, result in an error budget consistent with the goal of measuring salinity with a global RMS accuracy of 0.2 psu each month with a spatial resolution of $150 \mathrm{~km}[7]$.

\section{STATUS}

Aquarius and the Aquarius/SAC-D observatory have been working well. A worrisome issue with the star tracker has been resolved. It was noticed at the beginning of the mission that the star tracker performance was below expectations and degrading. Furthermore, when the Moon came within range, a noisy signal often triggered the attitude control system to put the spacecraft into safe-hold mode. The problem was tracked to noise in the detector array and the problem was corrected by reducing the array temperature and making some adjustments to the software in the attitude control system.

From the beginning, the Aquarius radiometers have performed close to predictions based on the forward model simulator assembled to predict the expected antenna temperatures [8]. After a bias was removed, the performance has been within specifications. However, there is a slight drift in gain (about $1 \mathrm{~K}$ during the first year of operations but much less recently). The drift has had an exponential shape as a function of time with small variations about the mean exponential shape dubbed "wiggles". Although the drift is small and within specification, it is noticeable in the salinity maps (e.g. when for looking at inter-annual variations in the global salinity field). It is removed as part of the radiometer calibration.

The initial retrievals showed a difference in the salinity maps produced on ascending and descending orbits. This has 
been traced to the celestial background radiation reflected from the surface into the radiometer main beam. The problem appears to be inadequacy of the scattering theory used to correct completely for the effect of roughness (waves). An empirical correction has been developed which removes the "bias" and will in appear in the V3.0 of the data products to be released in May, 2014.

\section{EXAMPLES}

Aquarius salinity data products are available to the public from the NASA Physical Oceanography DAAC at:

\section{- $\quad$ www.podaac.jpl.nasa/gov/aquarius}

which also includes user guides and other relevant documentation (e.g. ATBD for the radiometer and scatterometer). Aquarius is also producing a soil moisture product (i.e. global maps) which are available from the National Snow and Ice Data Center:

\section{- www.nsidc.org/data/aquarius/index.html}

Examples of the data products, such as salinity soil moisture maps and plots of radiometer and scatterometer RFI, are available at the Aquarius education and public outreach website at:

\section{- $\quad$ www.aquarius.umaine.edu/cgi/index.htm}

where there is also background and historical information and links to other sources of information about Aquarius.

Figure 2 is an example of the mean salinity field produced by Aquarius after its first year in operation. It shows the general features expected of the salinity field such as the more saline Atlantic Ocean compared to the Pacific Ocean and the fresh belt along the inter-tropical convergence zone due the relatively high fresh water flux (precipitation). The shorter term maps (e.g. www.aquarius.umain.edu) show interesting dynamic features associated with such events as changes in the outflow from the Amazon and the monsoon in India.

\section{CONCLUSIONS}

Aquarius is doing well. An improved data product (Version 3.0) is soon to be released (scheduled for May, 2014.

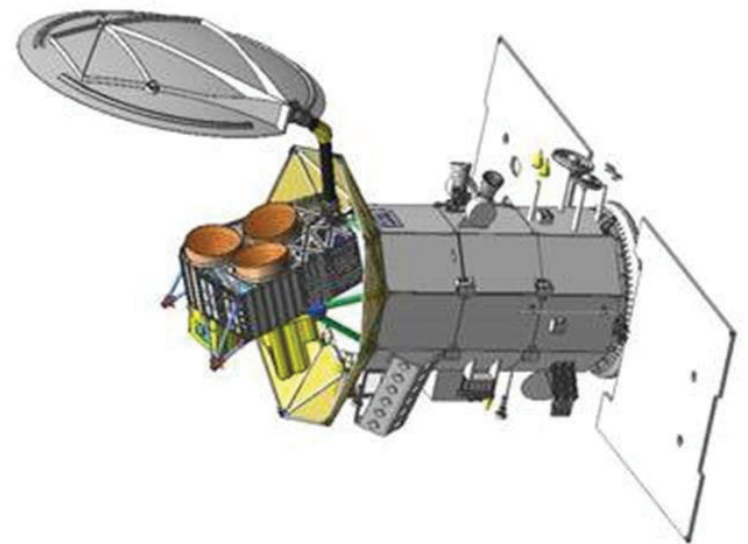

Figure 1. The Aquarius/SAC-D observatory in deployed configuration. Aquarius is the structure on the left.
This will have a number of improvements, including a better calibration at the warm end (land) and reduction in the bias between salinity retrieved on ascending and descending passes. The new version also includes an improved definition of flags and masks used for identifying regions suitable for use in calibration and for transferring data from Level 2 to Level 3 (global gridded maps). Work to improve the products continues. For example, the effect of rain is under investigation and plans are being made to incorporate data from the SAC-D Microwave Radiometer (MWR) into the Aquarius processing to provide a rain flag.

\section{REFERENCES}

[1] D.M. Le Vine, G.S.E. Lagerloef, R. Colomb, S. Yueh, F. Pellerano, "Aquarius: An instrument to monitor sea surface salinity from space", IEEE Trans. Geosci. Remote Sens., vol 45 (\#7), pp. 2040-2050, July, 2007.

[2] J. Font, G.S.E. Lagerloef, D.M. Le Vine, A. Camps and O-Z. Zanife, "The determination of Surface Salinity with the European SMOS Space Mission”, IEEE Trans. Geosci. Remote Sens., vol 42 (\#10), pp 21962205, October, 2004.

[3] D. M. Le Vine, G.S.E. Lageroef, S. E. Torrusio, "Aquarius and remote sensing of sea surface salinity from Space, IEEE Proc., vol 98 (\#5), pp 688 - 703, May, 2010.

[4] S.H. Yueh, "Estimates of Faraday rotation with passive microwave polarimetry for microwave remote sensing of earth surfaces," IEEE Trans. Geosci. Remote Sens., Vol 38 (\#5), pp. 2434-2438, September, 2000 .

[5] D. M. Le Vine, S. Abraham, C. Utku and E.P. Dinnat, "Aquarius Third Stokes Parameter Measurements: Initial Results", IEEE Geosci. Remote Sensing Letter, Vol 10 (\#3), pp. 520-524, May, 2013.

[6] E.P. Dinnat and D. M. Le Vine, "Impact of sun glint on salinity remote sensing: An example with the Aquarius Radiometer", IEEE Trans. Geosci. Remote Sens., Vol 46 (\#10), pp. 3137-3150, Ocatober, 2008.

[7] G.S.E. Lagerloef et al, "The Aquarius/SAC-D mission: Designed to meet the salinity remote sensing challenge", Oceanography, Vol21 (\#1), pp 69-81, March, 2008.

[8] D.M. Le Vine, E.P. Dinnat, S. Abraham, P. de Matthaeis and F.J. Wentz, "The Aquarius simulator and cold-sky calibration", IEEE Trans. Geosci. Remote Sens., Vol 49 (\#9), pp. 3198-3210, September, 2011.

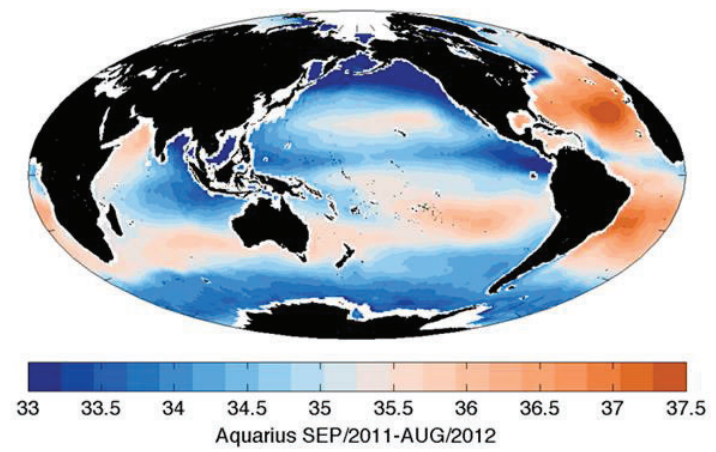

Figure 2. The global sea surface salinity field. This is an average of the first year of Aquarius measurements. 